\title{
Effects of methylprednisolone on femoral bone marrow: age-dependent susceptibility
}

\author{
Wing P. Chan ${ }^{1}$, Tzong-Fu Kuo ${ }^{2}$, Yun-Ho Lin ${ }^{3}$, Chia-Chun Chen ${ }^{4}$, Shu-Ru Yang ${ }^{4}$, Sydney Huang ${ }^{5}$, \\ Ching-Chuan Jiang ${ }^{6}$
}

${ }^{1}$ Department of Radiology, School of Medicine, College of Medicine, Taipei Medical University; Department of Radiology, Wan Fang Hospital, Taipei Medical University, Taipei - Taiwan

${ }^{2}$ Graduate Institute of Veterinary Medicine, National Taiwan University, Taipei - Taiwan

${ }^{3}$ Department of Pathology, School of Medicine, College of Medicine, Taipei Medical University, Taipei - Taiwan

${ }^{4}$ Department of Radiology, School of Medicine, College of Medicine, Taipei Medical University, Taipei - Taiwan

${ }^{5}$ Department of Radiology, Wan Fang Hospital, Taipei Medical University, Taipei - Taiwan

${ }^{6}$ Department of Orthopedic Surgery, National Taiwan University and Hospital, Taipei - Taiwan

\begin{abstract}
Purpose: We aimed to test our primary hypothesis that the effects of methylprednisolone on bone marrow in chickens are age-sensitive and increase with prolonged treatment and our secondary hypothesis that the effects of methylprednisolone on bone marrow can have individual effects.

Methods: Sixteen control (group A) and 29 methylprednisolone-treated (group B) chickens were categorised by age: pubertal chicks (subgroups A1, B1), young hens (A2, B2), and adult hens (A3, B3). Histologic evaluation 12 to 50 weeks after the start of methylprednisolone treatment included fat cell proliferation, trabecular bone loss, necrosis of bone and marrow, and new bone formation in the femoral head, neck, and intertrochanteric area.
\end{abstract}

Results: There were significant differences between groups $A 1$ and $B 1$ in new bone formation in the femoral neck $(P=0.048)$ and fat cell proliferation in the femoral head $(P=0.008)$ and neck $(P=0.048)$. New bone formation in the femoral head was also significantly different $(P=0.023)$ between groups $A 2$ and B2. No differences were noted between groups $A 3$ and $B 3$ (all $P>0.05$ ). Necrosis of bone and marrow was observed in four control and three methylprednisolone-treated chickens $(P>0.05)$. Significant new bone formation and fat cell proliferation in pubertal and young chickens occurred 12 to 19 weeks after administration of high-dose methylprednisolone.

Conclusions: Younger animals may be more susceptible to methylprednisolone, and responses to methylprednisolone in femoral marrow may vary among individuals.

Keywords: Adipogenesis, Animals, Bone marrow, Steroids, Osteonecrosis

Accepted: April 8, 2013

\section{INTRODUCTION}

Osteonecrosis of the femoral head is defined by the death of subchondral osteocytes resulting in empty lacunae and surrounding bone marrow necrosis, followed by a reparative process. It is frequently complicated by articular collapse $(1,2)$. Although the pathogenesis of osteonecrosis of the femoral head is still unknown, corticosteroid use has been suggested as a major predisposing factor (1-3). In a human study, patients with steroid-induced osteonecrosis were significantly younger and fewer presented with a collapsed femoral head than patients with alcohol-induced osteonecrosis (4).

Many studies have examined different animal models for induction of osteonecrosis of the femoral head with corticosteroids (5-18), but with limited success (19). To simulate 
functional loading to the area of insult in human anatomy, biped chickens have been administered weekly intramuscular injections of methylprednisolone $(3 \mathrm{mg} / \mathrm{kg})$ for 14 (20) or 24 weeks (3), but still no femoral head collapse was observed.

Osteonecrosis can be induced after either high- or lowdose short-term administration of corticosteroids $(13,17)$. Osteonecrosis induced by corticosteroids has been recognised mainly in the metaphysis and diaphysis in animals $(3,13,21,22)$. In rabbits, treatment with methylprednisolone, but not prednisolone or triamcinolone, significantly increases the incidence of osteonecrosis (23).

We tested our primary hypothesis that the effects of methylprednisolone on bone marrow are age-sensitive and increase with prolonged treatment in chickens. Our secondary hypothesis was that the effects of methylprednisolone on bone marrow vary among individuals.

\section{MATERIALS AND METHODS}

The Institutional Animal Care and Use Committee at National Taiwan University managed by Taiwan Advance Bio-Pharmaceutical Inc. approved the breeding of the animals and the protocol of this study.

This was a case-control study to test the response of methylprednisolone on femoral bone marrow in chickens of different ages. Animals were also eligible for a separate study, not reported here, in which their intraosseous circulation was assessed by dynamic magnetic resonance imaging (MRI). A total of 57 white female Leghorn chickens (weight, 1.8 to $3.5 \mathrm{~kg}$ ) were initially recruited. Animals were weighed at the beginning of the experiment and on the first day of each week. The induction dosage of methylprednisolone was adjusted accordingly. All chickens were housed in well-ventilated cages and fed with a standard diet (100 g/day/chicken) and water. For infection prophylaxis, all chickens received penicillin $20,000 \mathrm{U} / \mathrm{kg}$ in a single dose every other day and streptomycin $50 \mathrm{mg} / \mathrm{kg}$ twice a week. All animal husbandry and handling procedures followed the standard operating procedures of our institution for laboratory animal breeding and management.

The animals were divided into two main groups. In group $A$ (control), 16 animals were divided into three subgroups by age at recruitment: four in subgroup A1 (pubertal chicks), eight in A2 (young hens), and four in A3 (adult hens). This group received no methylprednisolone intervention. In group B, 38 chickens received different dosages and methylprednisolone injection for different durations (Solumedrol, UpJohn Laboratories, Kalamazoo, MI) in the pectoralis major muscle. The study followed the same dosages ( $3 \mathrm{mg} /$ $\mathrm{kg} / \mathrm{wk}$ ) as in Cui et al's (3) chicken model and assessed responses at various durations of steroid induction. To assess the effects of a higher dose, we modified Yamamoto et al's (14) study of rabbits and tested their half dose $(9 \mathrm{mg} / \mathrm{kg})$ for a longer duration of steroid use.

All animals were euthanised at the scheduled time by being placed into a closed chamber of $100 \%$ carbon dioxide at a flow rate of $20 \%$ chamber volume per minute for 10 minutes (24). A senior veterinary surgeon, who has 25 years of experience practicing surgery, excised both femurs of each animal. Nine animal specimens from group B were excluded: six $(16 \%)$ died during the induction period and the specimens from three chickens technically failed during preparation for histology. Of the six, five (four, B2; one, B3) died from heart failure after anaesthesia during MRI examination for the other study; one (A3 group) died between the breeding place and the MRI scanner when transportation was prolonged because of an earthquake. Finally, 29 chickens were classified according age at recruitment and the treatment regimen (Tab. I).

TABLE I - AGE GROUPS AND TREATMENTS OF 45 CHICKENS $^{*}$

\begin{tabular}{|c|c|c|c|c|}
\hline Group & No. & $\begin{array}{l}\text { Age at } \\
\text { recruitment } \\
\text { (weeks) }\end{array}$ & $\begin{array}{l}\text { Age at sacri- } \\
\text { fice (weeks, } \\
\text { mean } \pm S D)^{\star}\end{array}$ & $\begin{array}{l}\text { Methylprednisolone } \\
\text { administration }\end{array}$ \\
\hline$A-1$ & 4 & - & $16 \pm 9$ & 0 \\
\hline$A-2$ & 8 & - & $61 \pm 16$ & 0 \\
\hline$A-3$ & 4 & - & $102 \pm 1$ & 0 \\
\hline B-1 & 5 & 7 & $27 \pm 1$ & $\begin{array}{l}9 \mathrm{mg} / \mathrm{kg} \text { every other day } \times \\
19 \text { weeks ( } 66 \text { doses) }\end{array}$ \\
\hline \multicolumn{5}{|l|}{ B-2 } \\
\hline B-2a & 6 & 31 & $44 \pm 1$ & $\begin{array}{l}3 \mathrm{mg} / \mathrm{kg} / \text { week } \times 12 \text { weeks } \\
\text { (12 doses) }\end{array}$ \\
\hline$B-2 b$ & 6 & 31 & $51 \pm 1$ & $\begin{array}{l}3 \mathrm{mg} / \mathrm{kg} / \text { week } \times 19 \text { weeks } \\
(19 \text { doses) }\end{array}$ \\
\hline B-2c & 4 & 29 & $69 \pm 1$ & $\begin{array}{l}3 \mathrm{mg} / \mathrm{kg} / \text { week } \times 40 \text { weeks } \\
\text { (40 doses) }\end{array}$ \\
\hline$B-2 d$ & 3 & 30 & $68 \pm 0$ & $\begin{array}{l}9 \mathrm{mg} / \mathrm{kg} \text { every other day } \times \\
38 \text { weeks ( } 130 \text { doses) }\end{array}$ \\
\hline B-3 & 5 & 52 & $102 \pm 3$ & $\begin{array}{l}9 \mathrm{mg} / \mathrm{kg} \text { every other day } \times \\
50 \text { weeks (172 doses) }\end{array}$ \\
\hline
\end{tabular}

${ }^{*} 9$ specimens were excluded from the analysis ( 6 chickens died, 3 inadequate specimens). 
The proximal two-thirds of each femur was dissected and fixed in $10 \%$ buffered neutral formalin for three days, then decalcified in $5 \%$ formic acid solution. After decalcification, the right femurs were cut in half longitudinally on a coronal plane, and the left femurs were cut at the femoral head, neck and intertrochanteric area on an axial plane. The specimens were then embedded in paraffin, cut into four to six 3 to $4 \mu \mathrm{m}$ serial sections (frontal, one to three; head, neck, intertrochanter, one for each) with a microtome (Shandon Retraction AS 325), and stained with haematoxylin and eosin.

A senior pathologist, who has 15 years' experience in skeletal pathology, interpreted all specimens without knowledge of the animals' age or group. The histology changes observed as consistent between serial sections were classified as fat cell proliferation (proliferation of bone marrow adipocytes) (10), trabecular bone loss (thinning of bone trabeculae or osteoporosis) (10), necrosis of bone and marrow (uniform loss of lacunar osteocytes or empty lacunae accompanied by marrow cell debris) $(1,10,13)$, and new bone formation (new appositional bone repair) (1) in the femoral head, neck, and intertrochanteric area. The severity of these findings was graded as 0 (few or subtle), I (many or obvious), and II (numerous or diffuse) (25).

Statistical analysis used Fisher's exact test to determine any significant difference between control and methylprednisolone-induced animals. A P value of less than 0.05 was considered to indicate a statistically significant difference. The statistical power reached 0.803 (26).

\section{RESULTS}

Groups A1 and B1 (pubertal chicks) showed statistically significant differences: in the femoral neck, there was new bone formation in all five of the methylprednisolone-treated chickens while of the four control chickens, one was classified as severity I and one as severity II $(P=0.048)$; there was fat cell proliferation in all of the methylprednisolone-treated group, while among the controls, one was classified as severity I and two as severity II $(P=0.048)$ (Figs. 1, 2); in the femoral head there was fat cell proliferation in all chickens in the treated group and none in the control group $(P=0.008)$.

In groups A2 and B2 (young hens), only new bone formation in the femoral head was statistically significantly

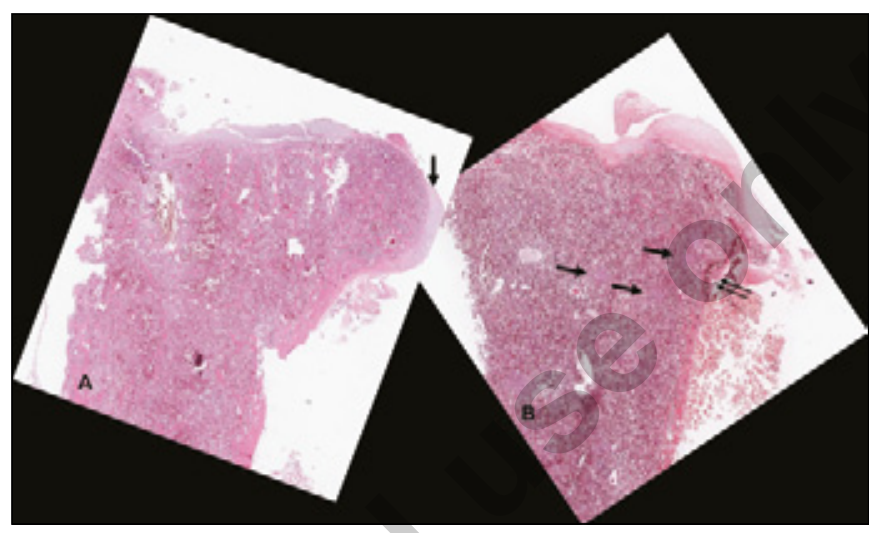

Fig. 1 - Photomicrographs of the proximal femur (midcoronal plane) of: $\boldsymbol{A})$ control young chicken; and $\boldsymbol{B}$ ) experimental young chicken after 19 weeks of steroid injection. (A) The femoral head is curvilinear. The cartilage is of uniform thickness (arrow), whereas the other side is dislodged due to suboptimal preparation. (B) The surface of articular cartilage is thicker than in the control femoral head. A subcapital fracture (double thin arrows) is noted. The section shows loss of primary bone trabeculae, which are replaced by marked secondary bone trabeculae, forming sclerosing nodules (bony callus) (thick arrows) (H\&E).

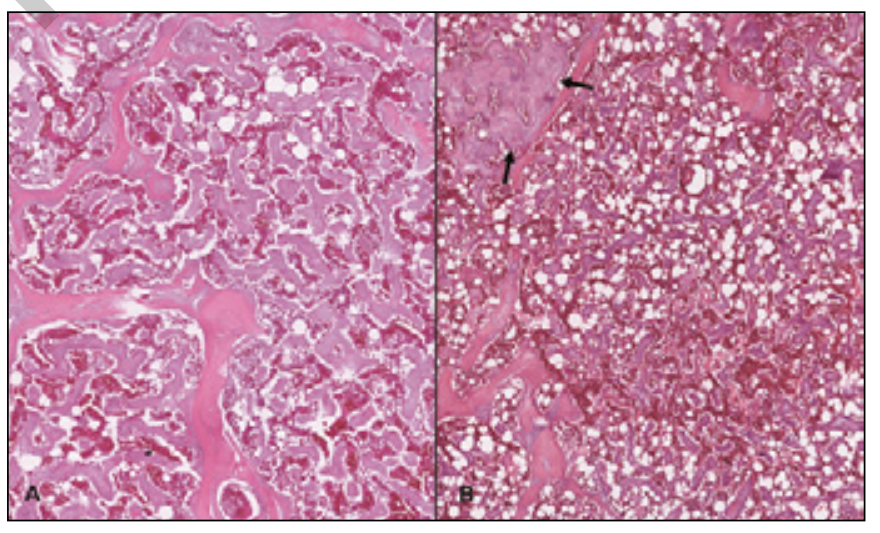

Fig. 2 - Photomicrographs of the femoral head of: $\boldsymbol{A})$ control young chicken; and B) experimental young chicken after 19 weeks of steroid injection. (A) The section shows appropriate fatty cells and vacuoles. Thickened primary bone trabeculae with secondary bone trabeculae are noted $(H \& E)$. (B) The section shows loss of primary bone trabeculae, which are replaced by marked secondary bone trabeculae, forming sclerosing nodules (arrows). Note the increase in fatty vacuoles ( $H \& E)$.

different between methylprednisolone-induced groups $(19 / 19,100 \%)$ and control chickens $(6 / 8,75 \%)(P=0.02)$. This was not significantly related to the different durations of methylprednisolone intervention among subgroup B2 animals (B2a vs A2, B2b vs. A2, B2c vs A2, all $P>0.05)$. 
In the adult hens (groups A3 and B3), there were no statistically significant differences in different histologic parameters at any of the three anatomic sites (all $P>0.05$ ).

Necrosis of bone and marrow was noted in three treated young hens (B1, 1/5; B2a, 1/6; B2b, 1/6) and four control chickens (A2, 1/8; A3, 3/4) (Fig. 3), but differences did not reach statistical significance $(P>0.05)$. In the femoral head there was necrosis of bone and marrow in one chicken (Tab. II). One chicken treated for 19 weeks had a cortical fracture with reparative response. One control chicken (age at sacrifice, 102 weeks) showed articular collapse of the right femoral head.

In group $A$, there were no statistically significant differences among the three age groups in the different histological parameters at three anatomic femoral sites (all $\mathrm{P}>0.05$ ) (Tab. II).

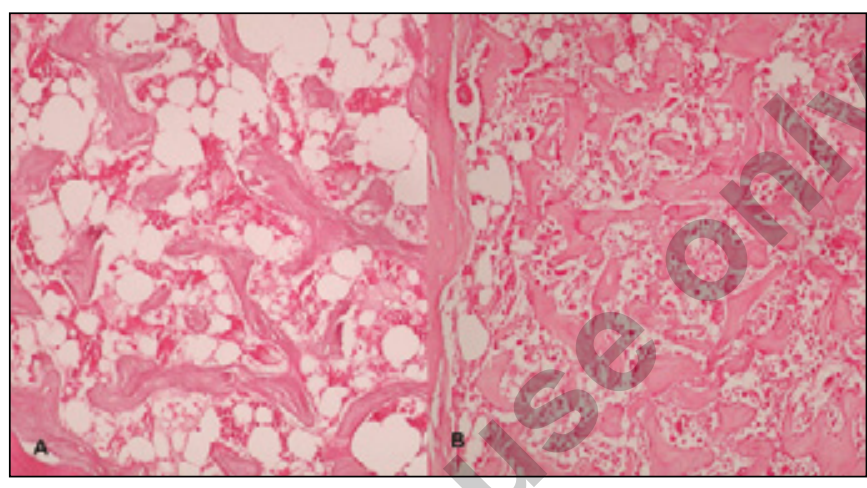

Fig. 3 - Photomicrographs of the femoral intertrochanteric area of: $\boldsymbol{A})$ control adult chicken; and $\boldsymbol{B}$ ) experimental young chicken after 19 weeks of steroid injection. (A) The section shows mild marrow necrosis. There is obvious proliferation of fat $(H \& E)$. (B) The section shows mild trabecular necrosis with focal collapse $(H \& E)$.

TABLE II - INCIDENCE OF HISTOLOGIC FINDINGS AT DIFFERENT FEMORAL SITES IN CONTROL VERSUS METHYLPREDNISOLONE-TREATED CHICKENS

\begin{tabular}{|c|c|c|c|c|c|c|c|c|c|c|c|c|c|c|c|c|c|c|}
\hline \multirow[t]{2}{*}{ Group } & \multicolumn{9}{|c|}{ Control $(n=16)$} & \multicolumn{8}{|c|}{ Treated $(n=29)$} & \\
\hline & \multicolumn{3}{|c|}{$A-1$} & \multicolumn{3}{|c|}{ A-2 } & \multicolumn{3}{|c|}{$A-3$} & \multicolumn{3}{|c|}{ B-1 } & \multicolumn{3}{|c|}{ B-2 $^{\dagger}$} & \multicolumn{3}{|c|}{ B-3 } \\
\hline No. & \multicolumn{3}{|c|}{4} & \multicolumn{2}{|c|}{8} & 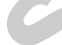 & \multicolumn{3}{|c|}{4} & \multicolumn{3}{|c|}{5} & \multicolumn{3}{|c|}{19} & \multicolumn{3}{|c|}{5} \\
\hline \multicolumn{19}{|c|}{ Necrosis of bone and marrow } \\
\hline Femoral head & 4 & 0 & 0 & 8 & 0 & 0 & 3 & 1 & 0 & 5 & 0 & 0 & 19 & 0 & 0 & 5 & 0 & 0 \\
\hline Intertrochanter & 4 & 0 & 0 & 7 & 1 & 0 & 2 & 2 & 0 & 4 & 1 & 0 & 17 & 2 & 0 & 5 & 0 & 0 \\
\hline \multicolumn{19}{|c|}{ Trabecular bone loss } \\
\hline Femoral head & 4 & 0 & 0 & 6 & 2 & 0 & 4 & 0 & 0 & 5 & 0 & 0 & 18 & 1 & 0 & 5 & 0 & 0 \\
\hline Femoral neck & 4 & 0 & 0 & 7 & 1 & 0 & 4 & 0 & 0 & 5 & 0 & 0 & 18 & 1 & 0 & 5 & 0 & 0 \\
\hline Femoral neck & 2 & 1 & $1^{a}$ & 1 & 3 & 4 & 0 & 3 & 1 & 0 & 5 & $0^{\mathrm{a}}$ & 0 & 9 & 10 & 0 & 3 & 2 \\
\hline Intertrochanter & 2 & 1 & 1 & 1 & 3 & 4 & 0 & 2 & 2 & 0 & 2 & 3 & 0 & 6 & 13 & 0 & 3 & 2 \\
\hline \multicolumn{19}{|l|}{ Fat cell proliferation } \\
\hline Femoral head & 4 & 0 & $0^{\mathrm{b}}$ & 6 & 2 & 0 & 2 & 2 & 0 & 0 & 5 & $0^{b}$ & 13 & 5 & 1 & 0 & 4 & 1 \\
\hline Femoral neck & 1 & 1 & $2^{c}$ & 5 & 2 & 1 & 3 & 1 & 0 & 0 & 5 & $0^{c}$ & 9 & 10 & 0 & 2 & 3 & 0 \\
\hline Intertrochanter & 0 & 2 & 2 & 2 & 4 & 2 & 1 & 3 & 0 & 0 & 5 & 0 & 4 & 9 & 6 & 0 & 4 & 1 \\
\hline
\end{tabular}

*Graded as 0 (few or subtle), I (many or obvious), and II (numerous or diffuse).

${ }_{+}^{+}$: B-2 includes B-2a, B-2b, B-2c and B-2d.

Bold indicates a statistically significant difference of age-matched control versus treated group:

arepresents $A-1$ versus $B-1, P=0.0476$.

brepresents $A-1$ versus $B-1, P=0.0079$.

crepresents $A-1$ versus $B-1, P=0.0476$.

drepresents $\mathrm{A}-2$ versus $\mathrm{B}-2, \mathrm{P}=0.0226$. 


\section{DISCUSSION}

Our results showed significant differences in new bone formation and fat cell proliferation in the bone marrow of the femoral head and neck in pubertal and young treated chickens 12 weeks after induction by methylprednisolone. Necrosis of bone and marrow was also observed in this time window in the pubertal and young group in contrast to the young and adult control group. There was a wide range of individual susceptibility to methylprednisolone.

We did not examine the animals before 12 weeks after corticosteroid administration, so we were unable to assess differences between groups in initial bone changes such as trabecular bone loss (or osteoporosis). However, with longer follow-up (19 weeks), our study suggests that trabecular bone loss can be overcome by reparative new bone formation, which may prevent further development to articular collapse. We did not examine all sites of long bone, but rather the proximal two-thirds of the femur. However, even in biped chickens, used to mimic the human weightbearing course of osteonecrosis of the femoral head, the result was less than expected.

This study was the first attempt to test age-matched control and experimental animals with a histological grading scoring system. The lack of further quantitative analysis, such as use of micro-computed tomography to assess the bone changes, is a potential limitation, and interobserver and intraobserver variation may have led to bias. There could have been more fractures that were missed without radiographic analysis. Lack of lactate dehydrogenase $(\mathrm{LDH})$ assay to observe cell viability and genetic analysis to determine whether the response of methylprednisolone on femoral bone marrow will develop in a particular subject were also limitations. The population size in each subgroup was relatively small, and a larger number of animals may lead to better statistical power. Differences in loading, ambulation and biomechanics between the chickens and the human represent a limitation of the animal models. The mortality rate of methylprednisolone-treated chickens in our study (16\%) was lower than that in Cui's (3) and Erken's (20) studies (both 48\%).

Methyprednisolone can have individual effects. Dead trabeculae were found in $16 \%(4 / 25)$ of female chickens at 12 to 24 weeks (3) and $31 \%(8 / 26)$ of male chickens at 14 weeks (20) after methyprednisolone ( $3 \mathrm{mg} / \mathrm{kg} / \mathrm{wk})$ administration. We found a similar relatively low rate (10\%) in our treated female chickens (pubertal, 20\% (1/5) and young,
$8 \%(2 / 24))$. In Ikemura's study (27), there was a significant difference in the incidence of osteonecrosis between male (66.7\%) and female rabbits (21.7\%). Beside a sex-dependent difference, this observation could also be explained by genetic factors interacting with certain risk factors that play a role in establishing whether a subject will develop osteonecrosis (15). Interestingly, in our control group, bone and marrow necrosis also occurred in $13 \%$ of pubertal (1/8) and $75 \%$ of adult normal chickens (3/4). No pathological change in control chickens was noted in previous reports $(3,20)$. In humans, genes related to corticosteroid metabolism may determine patients' sensitivity to developing osteonecrosis of the femoral head (28). In a laboratory study, corticosteroids produced adipogenesis and stimulated expression of the fat-specific gene, 422(aP2), after long-term high-dose administration (3). Corticosteroids may direct bone marrow stromal cells into the adipocytic pathway, which is opposite to the osteoblastic pathway, and the altered function of bone marrow stromal cells can be responsible for the pathogenesis of osteonecrosis (29).

Age may be an important factor in the pathogenesis of steroid-induced osteonecrosis. In humans, patients with steroid-induced osteonecrosis were significantly younger (average age, 39 vs 49 years) and fewer presented with a collapsed femoral head (62\% vs $90 \%)$ than patients with alcohol-induced osteonecrosis (4); similar results in chickens were noted in this study. The cause of osteonecrosis in our adult control chickens is obscure. The reason that no osteonecrosis occurred in adult chickens treated with corticosteroid over a long period is also not known. Our study monitored the effects of methylprednisolone injection for as long as 50 weeks, during which time no necrosis of the bone and marrow resulted. One previous study reported that neither rabbits nor rats showed osteonecrosis in the femoral and humeral heads nine months after corticosteroid administration (6). This could be due to a reversible repair process before necrosis of bone and marrow occurred. Results of our study indicated no induction of osteonecrosis in adult chickens with a long duration of high-dose corticosteroid. We could also reasonably suspect that the effects of methylprednisolone on pubertal or young animals may be a transient effect.

Bouteiller et al (30) in 1983 first attempted to use biped geese for the induction of osteonecrosis of the femoral head, with administration of high-dose corticosteroid for 22 weeks, but no marrow necrosis resulted. Later Cui et al (3) and Erken et al (20) gave chickens weekly 
intramuscular injections of methylprednisolone $(3 \mathrm{mg} / \mathrm{kg}$ ) for 24 weeks, but no femoral head collapse was reported. A single high-dose $(20 \mathrm{mg} / \mathrm{kg})$ methylprednisolone injection was found to be capable of inducing multifocal osteonecrosis over four weeks and appositional bone formation over 10 weeks in rabbits (13) A low-dose $(0.8 \mathrm{mg})$ course of methylprednisolone via daily or alternate-day injections can induce osteocyte death, necrotic debris, osteoporosis, and intravascular fat emboli in the femur of rabbits over 18 weeks (17).

Most previous animal studies have conducted histopathologic examinations at six to 20 weeks after corticosteroid treatment $(13,19)$. Osteonecrosis can be observed as early as four weeks after corticosteroid induction in rabbits, and thereafter the lacunae are gradually replaced by reparative tissue (13). In studies of chickens, fat cell proliferation became clearly distinguishable after one week (3) and three weeks (20); empty lacunae and focal marrow necrosis were noted at six and 12 weeks $(3,20)$, whereas large areas of subchondral bone death with new bone formation were found in four of 12 chickens at 12 and 24 weeks in Cui's study (3) and 24 out of 26 chickens at 14 weeks in Erken's study (20). Similarly, in our study, at the first follow-up time point 12 weeks after corticosteroid administration, significantly different new bone formation and fat cell proliferation were revealed, as compared to the control animals. Therefore, the effects of methyprednisolone can be more reliably observed after relatively short-term, high-dose administration limited to pubertal and young chickens rather than long-term regimens in adult chickens.

Previous reports have indicated that osteonecrosis-prone sites may differ in animal species (13). Osteonecrosis has only been recognised in the metaphysis and diaphysis $(3,13,21)$, as in our study, and rarely in the epiphysis of the femur and humerus in animals $(5,16,31)$. In our study, one control adult chicken showed unilateral articular collapse.
Predisposing factors could include immunosuppressive viruses and non-infective bone disorders (32).

In summary, in this study, we observed that methylprednisolone-induced necrosis of bone and marrow can occur in pubertal and young chickens, with a short course of induction, and that these findings can be an individual effect in chickens. We also observed sporadic events: a cortical fracture in a methylprednisolone-induced young chicken and articular collapse in a control adult chicken. Administration of high-dose methylprednisolone for 12 to 19 weeks can induce significant new bone formation and fat cell proliferation in the femoral head and neck in pubertal and young chickens. Younger animals may be more susceptible to methylprednisolone, and responses to methylprednisolone in femoral marrow may vary among individuals.

\section{ACKNOWLEDGMENTS}

The authors wish to thank Yi-Fong Wang, MSc, Ya-Hui Chan, $B S c$, and Shan-Ru Ke, MSc, for data collection and literature reviews, Yen-Kuang Lin, MSc, for statistical analysis, Jie-Han Yang, BSc, for animal breeding and handling procedures.

Financial Support: This work was supported by the Department of Health, Taiwan, Republic of China for grant support (NHRI-EX939320EI, NHRI-EX94-9320EI, NHRI-EX95-9320EI).

Conflict of Interest: The authors declare no conflicts of interest.

Address for correspondence:

Wing P. Chan, MD

Department of Radiology

Wan Fang Hospital, Taipei Medical University

111 Hsing Long Road, Section 3

Taipei 116, Taiwan

wingchan@tmu.edu.tw

\section{REFERENCES}

1. Chernetsky SG, Mont MA, LaPorte DM, Jones LC, Hungerford DS, McCarthy EF. Pathologic features in steroid and nonsteroid associated osteonecrosis. Clin Orthop Relat Res. 1999;(368):149-61.

2. Assouline-Dayan $Y$, Chang $C$, Greenspan A, Shoenfeld $Y$, Gershwin ME. Pathogenesis and natural history of osteonecrosis. Semin Arthritis Rheum. 2002;32(2):94-124.
3. Cui Q, Wang GJ, Su CC, Balian G. The Otto Aufranc Award. Lovastatin prevents steroid induced adipogenesis and osteonecrosis. Clin Orthop Rel Res. 1997;344:8-19.

4. Castro FP Jr, Harris MB. Differences in age, laterality, and Steinberg stage at initial presentation in patients with steroid-induced, alcohol-induced, and idiopathic femoral head osteonecrosis. J Arthroplasty. 1999;14(6):672-6.

5. Gold EW, Fox OD, Weissfeld S, Curtiss PH. Corticosteroid-induced avascular necrosis: an experimental 
study in rabbits. Clin Orthop Relat Res. 1978;(135): 272-80.

6. Gosling DC, Sampson WF, MacLoed M. Susceptibility of the rabbit and rat to steroid osteonecrosis-an experimental study. Transplantation. 1987;43(5):751-3.

7. Horii T, Matsumoto T, Nishino M, Tomita K. Effects of steroids on femoral diaphyseal intramedullary circulation in rabbits. Arch Orthop Trauma Surg. 2002;122(9-10): 506-9.

8. Ichiseki T, Kaneuji A, Katsuda S, Ueda Y, Sugimori T, Matsumoto T. DNA oxidation injury in bone early after steroid administration is involved in the pathogenesis of steroid-induced osteonecrosis. Rheumatology (Oxford). 2005;44(4):456-60.

9. Korompilias AV, Gilkeson GS, Seaber AV, Urbaniak JR. Hemorrhage and thrombus formation in early experimental osteonecrosis. Clin Orthop Relat Res. 2001;(386):11-8.

10. Miyanishi $\mathrm{K}$, Yamamoto $\mathrm{T}$, Irisa $\mathrm{T}$, et al. Bone marrow fat cell enlargement and a rise in intraosseous pressure in steroid-treated rabbits with osteonecrosis. Bone. 2002;30(1): 185-90.

11. Nishimura T, Matsumoto T, Nishino M, Tomita K. Histopathologic study of veins in steroid treated rabbits. Clin Orthop Relat Res. 1997;(334):37-42.

12. Wang JG, Sweet DE, Reger SI. Fat-cell changes as a mechanism of avascular necrosis of the femoral head in cortisonetreated rabbits. J Bone Joint Surg Am. 1977;59(6):729-35.

13. Yamamoto T, Irisa T, Sugioka $Y$, Sueishi K. Effects of pulse methylprednisolone on bone and marrow tissue: corticosteroid-induced osteonecrosis on rabbits. Arthritis Rheum. 1997;40(11):2055-64.

14. Cui Q, Wang G-J, Balian G. Pluripotential marrow cells produce adipocytes when transplanted into steroid-treated mice. Connect Tissue Res. 2000;41(1):45-56.

15. Weinstein RS, Jilka RL, Parfitt AM, Manolagas SC. Inhibition of osteoblastogenesis and promotion of apoptosis of osteoblasts and osteocytes by glucocorticoids. J Clin Invest. 1998;102(2):274-82.

16. Glade MJ, Krook L. Glucocorticoid-induced inhibition of osteolysis and the development of osteopetrosis, osteonecrosis, and osteoporosis. Cornell Vet. 1982;72(1):76-91.

17. Drescher $\mathrm{W}$, Bünger $\mathrm{MH}$, Weigert $\mathrm{K}$, Bünger $\mathrm{C}$, Hansen ES. Methylprednisolone enhances contraction of porcine femoral head epiphyseal arteries. Clin Orthop Relat Res. 2004;(423):112-7.

18. Paolaggi JB, LeParc JM, Barres D, et al. [Experimental cortisone osteonecrosis. Early stages of bone marrow and trabecular lesions. Preliminary study in pigs]. [Article in French]. Rev Rhum Mal Osteoartic. 1983;50(3):171-4.
19. Conzemius MG, Brown TD. Animal Models of Osteonecrosis. Tech Orthop. 2001;16(1):90-7.

20. Erken, HY, Ofluoglu O, Aktas M, Topal C, Yildiz M. Effect of pentoxifylline on histopathological changes in steroidinduced osteonecrosis of femoral head: experimental study in chicken. Int Orthop. 2012;36(7):1523-8.

21. Matsui M, Saito S, Ohzono K, Sugano N, Saito M, Takaoka $\mathrm{K}$, Ono K. Experimental steroid-induced osteonecrosis in adult rabbits with hypersensitivity vasculitis. Clin Orthop Relat Res. 1992;(277):61-72.

22. Wu X, Yang S, Duan D, Zhang Y, Wang J. Experimental osteonecrosis induced by a combination of low-dose lipopolysaccharide and high-dose methylprednisolone in rabbits. Joint Bone Spine. 2008;75(5):573-78.

23. Miyanishi K, Yamamoto T, Irisa T, et al. Effects of different corticosteroids on the development of osteonecrosis in rabbits. Rheumatology (Oxford). 2005;44(3):332-6.

24. Hawkins P, Playle L, Golledge H, et al. Newcastle consensus meeting on carbon dioxide euthanasia of laboratory animals. 2006 Available at www.nc3rs.org.uk/CO2ConsensusReport. Accessed Jan 31, 2013.

25. Li SC, Lin CY, Kuo TF, Lin YH, Chen CC, Lin WN, Chan WP. Chicken model of steroid-induced bone marrow adipogenesis using proteome analysis: a preliminary study. Proteome Sci. 2010;8(1):47.

26. Faul F, Erdfelder E, Buchner A, Lang AG. Statistical power analyses using $G^{*}$ Power 3.1: Tests for correlation and regression analyses. Behav Res Methods. 2009;41(4):1149-60.

27. Ikemura S, Yamamoto T, Nishida K, Motomura G, Iwamoto Y. Gender difference in the development of steroid-induced osteonecrosis in rabbits. Rheumatology (Oxford). 2010; 49(6):1128-32.

28. Asano T, Takahashi KA, Fujioka M, et al. Genetic analysis of steroid-induced osteonecrosis of the femoral head. J Orthop Sci. 2003;8(3):329-33.

29. Wang GW, Cui Q, Balian G. The Nicolas Andry Award. The pathogenesis and prevention of steroid induced osteonecrosis. Clin Orthop Rel Res. 2000;(370):295-310.

30. Bouteiller G, Arlet J, Blasco A, Vigoni F, Elefterion A. Is osteonecrosis of the femoral head avascular? Bone blood flow measurements after long-term treatment with corticosteroids. Metab Bone Dis Relat Res. 1983;4(5):313-8.

31. Yamamoto T, Hirano K, Tsutsui H, Sugioka Y, Sueishi K. Corticosteroid enhances the experimental induction of osteonecrosis in rabbits with Shwartzman reaction. Clin Orthop Relat Res. 1995;(316):235-43.

32. McMullin P. Diseases and syndromes: chickens and various species. In: McMullin P, eds. A pocket guide to: poultry health and disease. Sheffield: 5 M Enterprises Ltd. 2004. 